\title{
Preparation for the new diploma examination in implant dentistry
}

Please send any ideas for feature articles fo consideration to:

Rowena Milan,

British Dental Journal,

The Macmillan Building,

4-6 Crinan Street,

London

N1 9XW

Email:r.milan@nature.com

Paul Stone, Chairman of the Advisory Board in Implant Dentistry of the Royal College of Surgeons of Edinburgh, outlines the development of the new diploma examination in implant dentistry and indicates the candidate preparation that would be appropriate for the first diet, scheduled for October 28-30 2009.

In 2006, the Royal College of Surgeons of Edinburgh Dental Faculty created a new Advisory Board in Implant Dentistry. The Board was formed from a small group of senior clinicians and the task facing them was to create a diploma examination in implant dentistry that would be independent of any specific education or training programme. The Diploma Regulations have been approved by the Council of the College's Dental Faculty and begin by stating:

'The Diploma in Implant Dentistry of the Royal College of Surgeons of Edinburgh is an examination of core knowledge and competence in the field of implant dentistry. It is intended to test the candidate's competency at a level expected of a general practitioner with a particular interest in implant dentistry and will include aspects of minor augmentation. The diploma is not intended to test the candidate's competency or detailed knowledge of the more advanced procedures such as major bone grafting (block onlay grafting), sinus grafting or full arch prosthodontic rehabilitation.'

The aims of the examination are to allow the candidate to demonstrate core knowledge of implant dentistry and also to demonstrate a level of competence in the planning and execution of dental implant treatment.

\section{Learning outcomes and requirements}

The key to any modern examination is the creation of a list of 'learning outcomes'; these indicate what a candidate should be able to do and for the Diploma in Implant Dentistry (D.Imp.Dent RCSEd) there is a list detailing over 80 aspects of implant dentistry that will be assessed. These are under the headings:

- Clinical assessment skills

- Practical procedures

- The scientific basis of implant dentistry

- Appropriate attitudes to professional and clinical practice.

The examination is in three parts, which will be sat at the same diet and must be passed independently:

- Part 1 is a written examination consisting of two papers (single best answer and short answer questions)

- Part 2 is an objective structured clinical examination (OSCE) with multiple stations assessing clinical and practical skills

- Part 3 is a viva examination of the candidate's case presentation portfolio. This will consist of four case presentations and should include a range of cases demonstrating the candidate's skills. It must include at least one case of multiple tooth replacement and one case with over 12 months' documented follow-up.

The entry requirements for the diploma are the possession of a primary dental qualification and to have been

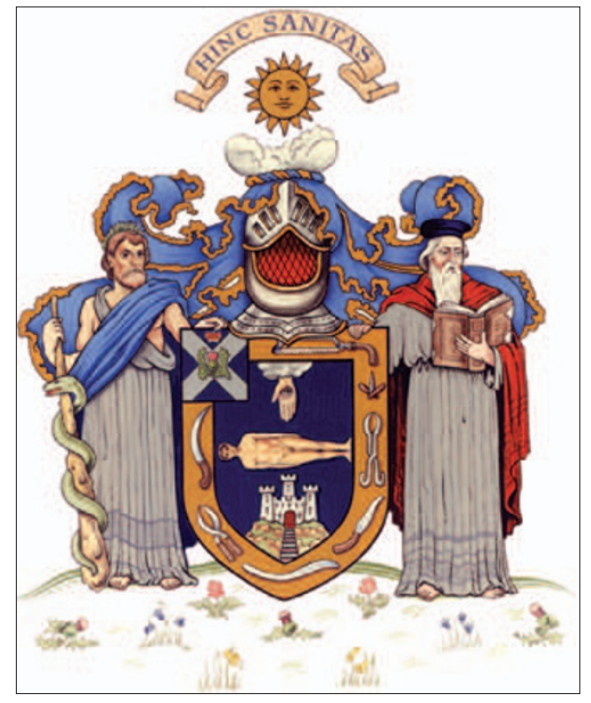

practising as a dentist for the equivalent of at least three years. Candidates will also be required to submit a logbook for assessment, before being allowed to sit the examination. The logbook should detail all aspects of activity related to implant dentistry over the past 12 consecutive months, including lectures attended, mentoring supervision and clinical activity. All entries should be accompanied by 'reflective comments' from the candidate.

\section{Candidate preparation and application}

The first diet for the Diploma has been delayed until later in 2009 due to the time taken to prepare the documentation required by the quality assurance process of the Edinburgh College, as well as 
the significant IT involvement to create a secure website structure to allow candidates to upload their cases and examiners to assess them. The Royal College recently held a very successful two-day examiner training event for the appointed D.Imp. Dent examiners and as a result, much of the necessary paperwork is now available from the College website (www. rcsed.ac.uk). Well over a hundred notes of interest to the College Examinations Department have already been made by potential diploma candidates, and it is anticipated that formal application to sit the examination will soon be available.

A number of academic and training institutions, as well as national and commercial organisations, have already intimated a wish to align their own programmes with the aims and learning outcomes of the Edinburgh College Diploma, to help prepare candidates. One of the unique features of the examina- tion is the opportunity for the candidate to undertake 'self-directed learning': to prepare for the examination at their own pace, attending independent and commercially-based training according to individual needs. It also means that by following the list of learning outcomes to guide the selection of appropriate training and mentoring, a broad, core level of knowledge and competence can be acquired. This will suit clinicians at all levels of experience and will reduce the duplication and cost often experienced with courses that combine teaching and assessment.

With less than 12 months to the first sitting, it is time for prospective candidates to start preparation. The logbook record sheet can be downloaded from the website and completed as part of the entry requirement (this can also be filled in retrospectively by more experienced candidates). As well as this, the four case presentations should be considered and documentation started following the outline suggestions in the 'Guidance to Candidate' document, also available online. For further information, please refer to the website or contact the College at the address in the information section.

\section{Information section}

The Royal College of Surgeons of Edinburgh

3 Hill Place, Edinburgh EH8 9DS

Phone: +440131 6689222

Fax: +4401316689218

Email: information@rcsed.ac.uk.

Paul Stone is a specialist in oral surgery, Consultant and Honorary Senior Lecturer in Oral Surgery at Edinburgh Dental Institute, Associate Specialist in Oral and Maxillofacial Surgery in Tayside, Honorary Clinical Teacher at Dundee University Dental School, Clinical Director of Blackhills Specialist Referral Dental Clinic in Perthshire and President-Elect of the European Association for Osseointegration (EAO).

DOI: 10.1038/sj.bdj.2008.1029

\section{Erratum}

\section{Applied occlusion (book/DVD set) Book review (BDJ 2008; 205: 519)}

It has been brought to our attention that in $B D J$ volume 205 issue 9, the incorrect price was given for the above book. The book and DVD set costs £52.50, not $£ 28.00$.

We apologise for any inconvenience caused. 